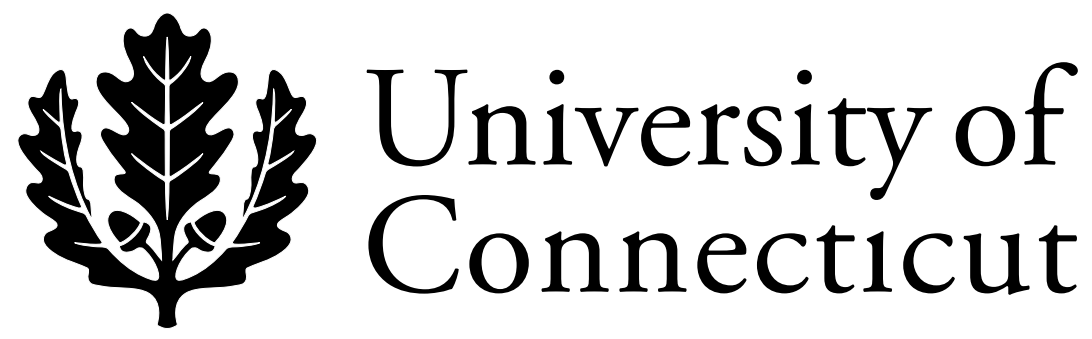

Department of Economics Working Paper Series

Criminal Solicitation, Entrapment, and the Enforcement of Law

Thomas J. Miceli

University of Connecticut

Working Paper 2005-17

June 2005

341 Mansfield Road, Unit 1063

Storrs, CT 06269-1063

Phone: (860) 486-3022

Fax: (860) 486-4463

http://www.econ.uconn.edu/ 


\begin{abstract}
This paper examines the optimal use of criminal solicitation as a law enforcement strategy. The benefits are greater deterrence of crime (due to the greater likelihood of apprehension), and the savings in social harm and apprehension costs as some offenders are diverted away from committing actual crimes through solicitation. The costs are the expense of hiring undercover cops and the greater likelihood of punishment. The optimal use of solicitation balances these factors. The paper also examines the justification for, and impact of, the entrapment defense, which exonerates those caught in a solicitation but otherwise not predisposed to commit a crime.
\end{abstract}

Journal of Economic Literature Classification: K14, K42

Keywords: Entrapment, criminal solicitation, law enforcement 


\section{Criminal Solicitation, Entrapment, and the Enforcement of Law}

\section{Introduction}

Law enforcers often solicit individuals to commit criminal acts as a way of lowering the cost of apprehending and convicting offenders. Examples include the use of undercover cops to apprehend drug dealers and prostitutes, or their customers. The presumption underlying the use of this strategy is that the target of the solicitation has a predisposition to commit the crime in question and therefore will likely commit an actual crime if not first apprehended by the police sting. Further, the increased threat of capture may deter some potential offenders from committing crimes in the first place. This logic suggests that criminal solicitation can be an effective tool in the arsenal of law enforcers.

The principal objection to solicitation, of course, is that it may induce a criminal act by someone who otherwise had no intention of breaking the law. This is the sort of person that the entrapment defense is meant to protect. Specifically, entrapment is the unlawful arrest of a person who was not "predisposed" to commit the crime in question (Posner, 2003, p. 231; Shavell, 2004, pp. 564-565). It is therefore aimed at protecting innocent people from overzealousness on the part of law enforcers. ${ }^{1}$

The purpose of this paper is to incorporate the use of criminal solicitation into the standard economic model of law enforcement (Polinsky and Shavell, 2000). The goals of the analysis are twofold. The first is to characterize the optimal use of solicitation as part of an overall enforcement strategy. This involves amending the standard model to allow search by potential offenders for "criminal opportunities," some of which may represent 
"stings" by law enforcers. For example, a drug dealer searches for buyers, knowing that some are undercover cops. We characterize two types of social benefits as arising from the use of this strategy: the first is a deterrence effect, which is due to the lower crime rate as some offenders are deterred from committing any crimes by the higher expected probability of apprehension; and the second is a diversion effect, which is the savings in social harm and enforcement costs as some offenders are diverted away from committing actual crimes through solicitation. At the optimum, these benefits are weighed against the marginal enforcement cost (the cost of the last undercover cop hired) plus the increased punishment cost (in the case of jail) due to the greater certainty of apprehension.

The second goal of the analysis is to examine the economic justification for, and impact of, the entrapment defense. We argue that, within the context of the model, two types of defendants can claim entrapment: those who would have refrained from seeking criminal opportunities altogether if not for the solicitation, and those who were actively seeking criminal opportunities but would not have found one but for the solicitation. Although the first type of offender has a legitimate claim from a legal perspective (given the above definition of entrapment), we show that such a claim is not justified by the model-i.e., any offender who would have been deterred in the absence of solicitation would be deterred a fortiori in its presence (all else equal). (This follow immediately from the deterrence effect described above.) Conversely, while some active searchers may legitimately claim that they would have failed to locate a criminal opportunity if not for solicitation (because solicitation increases the probability of success, by design), this

\footnotetext{
${ }^{1}$ Entrapments do not necessarily imply corrupt police officers, however, in that there is no necessary intent to falsely arrest someone (Stevenson, 2004). This is what distinguishes entrapment from "framing"
} 
is not a good legal (or economic) defense against prosecution because the very act of searching for an opportunity to commit a crime imposes an expected cost on society.

Although the model fails to explain why some truly innocent individuals are caught in police stings, we introduce that possibility into the model and examine the implications for the optimal use of solicitation. Not surprisingly, the possibility of false arrest reduces the desirability of this strategy by diluting its deterrence benefits and by creating a cost of wrongful punishment. The entrapment defense, to the extent that it mitigates the risk of false arrest, therefore actually promotes the use of criminal solicitation as an enforcement strategy.

\section{The Model}

The model differs from the standard economic model of crime in that it assumes potential offenders must search for criminal opportunities, and that, in a given time period, they may or may not be successful in locating one. In this context, the goal of criminal solicitation by law enforcers ("sting" operations) is to create what appear to be criminal opportunities (e.g., an undercover cop offering to buy drugs) as a way of diverting offenders from actual opportunities, thereby avoiding the social harm from the crime and saving on the costs of apprehension. To capture this formally, suppose that in the absence of solicitation there are $n$ potential criminal opportunities available to offenders seeking to commit an offense, and $x$ of these represent actual opportunities, where $x \leq n .^{2}$ For example, the $n$ opportunities might represent locations where drug dealers are known to hang out, and on a give night there is an actual dealer at $x$ of those

\footnotetext{
innocent people. On the latter activity, see Polinsky and Shavell (2001).

${ }^{2}$ The reason for allowing $x<n$ will become apparent in the discussion of the entrapment defense in Section 5 below.
} 
locations. Thus, a person who visits one of those $n$ locations at random in hopes of buying drugs will be successful with probability $x / n$.

Now suppose that the police create $y$ new opportunities, for example by disguising undercover cops as drug dealers. This makes the total number of potential criminal opportunities $n+y$, and the number of actual opportunities (including stings) $x+y$. As a result, the probability that a potential buyer will succeed in locating an actual opportunity (a willing dealer) is now $(x+y) /(n+y)$, and the probability that he will fail is $(n-x) /(n+y)$. If the buyer succeeds in locating a dealer, the conditional probability that it is a sting is $y /(x+y)$, in which case the buyer is apprehended and punished with certainty. In contrast, the conditional probability that it is an actual dealer is $x /(x+y)$, in which case the offender commits the crime and is only later caught and punished with probability $p<1$. This situation is depicted schematically in Figure 1.

The model makes use of the following additional notation:

$s=$ dollar value of the sanction (fine or prison) imposed on the offender if caught; ${ }^{3}$

$k(s)=$ social cost of punishment if it is prison, $k^{\prime}>0, k^{\prime \prime}<0$;

$e(y)=$ cost of a sting operation, $e^{\prime}>0, e^{\prime \prime}<0$;

$c(p)=$ cost of apprehension if the offender commits an actual crime, $c^{\prime}>0, c^{\prime \prime}<0$;

$h=$ social harm from an actual criminal act; ${ }^{4}$

$g=$ dollar gain to offender from committing an actual criminal act; ${ }^{5}$

$f(g), F(g)=$ density and distribution functions for $g\left(\right.$ where $\left.f=F^{\prime}\right)$.

\footnotetext{
${ }^{3}$ We assume that the punishment is the same whether or not the offender is caught in a sting.

${ }^{4} \mathrm{We}$ assume no harm is incurred when an offender is caught in a sting.

${ }^{5} \mathrm{We}$ also assume that the offender obtains no gain if he is caught in a sting.
} 
Figure 2 depicts the sequence of decisions of a potential offender, and shows the resulting payoffs to the offender $(\mathrm{O})$ and society $(\mathrm{S})$. The offender first draws a $g$ from the distribution $F(g)$ and compares the realized value to the threshold level $\hat{g}$ (to be derived below). If $g<\hat{g}$, the offender is deterred and the game ends. However, if $g \geq \hat{g}$, he searches for a criminal opportunity. ${ }^{6}$ As noted above, he succeeds in locating one with probability $(x+y) /(n+y)$, and fails with probability $(n-x) /(n+y)$. If he fails, the game ends, but if he succeeds, he is either caught immediately in a sting (which occurs with conditional probability $y /(x+y))$ and incurs punishment of $s$, or he commits an actual crime (which occurs with conditional probability $x /(x+y))$ and receives an expected payoff of $g-p s .^{7}$

As for the social payoffs, note first that society incurs the cost of a sting operation, $e(y)$, in all states of the world because the cost of setting up a sting (i.e., of deploying undercover cops) is independent of the offender's behavior (and hence independent of the realized value of $g$ ). In the case where punishment is jail time, the punishment cost, $k(s)$, is incurred with certainty if the offender is caught in a sting, and with probability $p$ if he commits an actual crime. In contrast, the cost of apprehension, $c(p)$, is only incurred if the offender commits an actual crime because only in that state do the police need to invest resources to capture him. Note that this specification is something of a departure from the standard economic model of crime in that it treats $c(p)$ as a variable cost rather than a fixed cost that is incurred regardless of the crime rate. In reality, of course, some apprehension costs are fixed (e.g., police salaries) and some are variable (detection efforts). We assume here that all costs are of the latter type because,

\footnotetext{
${ }^{6}$ We assume that the search is costless, though a cost could be added without altering the basic results.
} 
as noted above, one of the main benefits of criminal solicitation is to save on

apprehension costs. ${ }^{8}$ Finally, the social harm from an offense, $h$, is only incurred when the offender commits an actual crime.

Note that the offender's gain, $g$, is not counted as part of the social return in Figure 2. This is also a departure from the standard model and reflects an implicit assumption that the act being considered is strictly undesirable from a social perspective. ${ }^{9}$ This specification is based on the idea that the use of solicitations as an enforcement strategy is limited to acts that society definitely wants to deter. However, we show in Section 4.3 that our basic results do not depend on this assumption, suggesting that solicitation may be useful in a wider range of law enforcement settings.

\section{The Offender's Optimal Behavior}

Consider first the optimal behavior of a potential offender. Note that the only choice the offender makes is whether or not to seek a criminal opportunity once he has observed $g$. To examine this choice, we therefore need to calculate the threshold value $\hat{g}$. Based on the various possible outcomes in Figure 2 and the associated probabilities, we can calculate the offender's expected return from seeking a criminal opportunity, once he has observed $g$, to be $\mathrm{e}^{10}$

$$
\left(\frac{x}{n+y}\right)(g-p s)-\left(\frac{y}{n+y}\right) s .
$$

\footnotetext{
${ }^{7}$ Note that the current model collapses to the standard model in the case where $y=0$ and $x=n$.

${ }^{8}$ In fact, Becker's (1968) original paper specified apprehension costs as a positive function of both $p$ and the crime rate, or number of offenses, $O$. That is, he wrote the cost of apprehension as $c(p, O)$, where $c_{p}>0$ and $c_{O}>0$. Since then, however, most models have abandoned this dependence and simply written $c(p)$.

${ }^{9}$ See the general discussion of this point in Polinsky and Shavell (2000, p. 48, especially at note 12).

${ }^{10}$ Note that the unconditional probability of locating an actual opportunity (given search) is $[(x+y) /(n+y)][x /(n+y)]=x /(n+y)$, while the unconditional probability of being caught in a sting is $[(x+y) /(n+y)][y /(n+y)]=y /(n+y)$.
} 
The offender will seek an opportunity if and only if this return is positive, or if and only if

$$
g \geq(p+y / x) s \equiv \hat{g}
$$

It follows immediately from this condition that use of criminal solicitation as an enforcement strategy increases deterrence, all else equal (i.e., $\partial \hat{g} / \partial y>0$ ). This is due to the increased probability that the offender will be apprehended, conditional on his locating a criminal opportunity, as $y$ increases.

\section{Socially Optimal Solicitation}

This section derives the socially optimal level of criminal solicitation, taking as given the optimal behavior of offenders. We first consider the case where $s$ is a fine and later consider the case where it is jail time.

\subsection{Optimal Solicitation when Punishment is a Fine}

In the case where punishment is a fine, there is no social cost of punishment; that is $k(s) \equiv 0$. Combining the social costs of the various outcomes in Figure 2 with the relevant probabilities yields expected social costs of

$$
S C=\frac{x}{n+y} \int_{\hat{g}}^{\infty}[h+c(p)] d F(g)+e(y)
$$

where $\hat{g}$ is defined by (2). The social problem is the choose $y, p$, and $s$ to minimize these costs.

Consider first the optimal level of solicitation, denoted $y^{*}$. Taking the derivative of (3) with respect to $y$ yields the first-order condition

$$
\frac{x}{n+y}[h+c(p)] f(\hat{g})(s / x)+\frac{x}{(n+y)^{2}}[1-F(\hat{g})][h+c(p)]=e^{\prime}
$$


The two terms on the left-hand side of (4) reflect the marginal benefit of solicitation. The first term is the marginal benefit due to increased deterrence of crime as $y$ increases (the deterrence effect), while the second term is the expected savings in social harm and variable apprehension costs as some offenders are solicited to commit a crime by the police rather than committing an actual crime (the diversion effect). At the optimum, these marginal benefits are equated to the marginal cost of solicitation.

Consider next the optimal apprehension rate for those offenders who commit actual crimes. Taking the derivative of (3) with respect to $p$ (and rearranging) yields the first-order condition

$$
[h+c(p)] f(\hat{g}) s=[1-F(\hat{g})] c^{\prime} .
$$

This says that the marginal benefit of the greater deterrence from increased $p$ should be equated to the expected marginal cost. Given this condition, it is interesting to ask how use of solicitation affects the optimal apprehension rate. That is, are $y$ and $p$ complements or substitutes? Differentiating (5) with respect to $p$ and $y$ (and assuming that $\left.f^{\prime} \approx 0\right)^{11}$ shows that $\partial y / \partial p>0$. That is, the optimal apprehension rate goes up as $y$ is increased, implying that when solicitation is used as a part of an enforcement strategy, the police should pursue those who commit actual crimes more aggressively. Intuitively, since solicitation deters some crimes, it lowers the expected marginal cost of apprehension (by lowering the crime rate), thereby increasing the optimal $p$.

Finally, consider the optimal fine. As in standard enforcement models, the fine should be maximal (i.e., equal to the offender's wealth, $w$ ) because it is costless to increase the fine. As usual, this is proved by assuming that $s$ is less than maximal. Then,

\footnotetext{
${ }^{11}$ This amounts to assuming that $f$ is uniform (or nearly so).
} 
$s$ can be raised and $p$ lowered while holding $y$ fixed so that $\hat{g}$ is unchanged. But since this causes social costs to fall, the original $s$ could not have been optimal. Thus, $s^{*}=w$.

\subsection{Optimal Solicitation when Punishment is Jail Time}

When punishment takes the form of jail time, $k(s)>0$, and social costs become

$$
S C=\frac{1}{n+y} \int_{\hat{g}}^{\infty}[x(h+c(p))+(x p+y) k(s)] d F(g)+e(y),
$$

where $\hat{g}$ continues to be given by (2) (with $s$ now interpreted as the dollar cost to the offender of jail time). Optimal solicitation in this case is found by minimizing this expression with respect to $y$. The relevant first-order condition is

$$
\begin{gathered}
\frac{1}{n+y}[x(h+c(p))+(x p+y) k(s)] f(\hat{g})(s / x)+\frac{1}{n+y}[1-F(\hat{g})][x(h+c(p))+(x p+y) k(s)] \\
=\frac{1}{n+y}[1-F(\hat{g})] k(s)+e^{\prime}
\end{gathered}
$$

The two terms on the left-hand side again represent the marginal benefit of solicitation in the form of the deterrence and diversion effects, respectively. The only difference compared to the previous case is that these benefits now include the saved punishment costs for those crimes that are deterred. Offsetting this is the fact that the marginal cost of solicitation now also includes an extra term for the marginal punishment costs for those offenders who are caught by the sting. Since the net effect of introducing punishment costs is ambiguous, $y$ may be higher or lower here compared to the case where punishment is a fine.

The optimal choice of $p$ in this case solves the first-order condition

$$
[x(h+c(p))+(x p+y) k(s)] f(\hat{g}) s=[1-F(\hat{g})] x\left(c^{\prime}+k(s)\right),
$$


which has the same interpretation as (5), except for the addition of $k(s)$ on both sides. Finally, the optimal prison term solves the first-order condition

$$
[x(h+c(p))+(x p+y) k(s)] f(\hat{g})[p+(y / x)]=[1-F(\hat{g})](x p+y) k^{\prime}
$$

In contrast to the fine, the optimal prison term is not necessarily maximal but instead balances the marginal benefits from increased deterrence (the left-hand side) against the marginal cost of punishment (the right-hand side). ${ }^{12}$

\subsection{Offender's Benefit Counts in Social Welfare}

We conclude this section by asking whether the preceding results would be qualitatively different if the offender's benefit were counted in social welfare. (For simplicity, we limit the analysis to the case of fines.) Social welfare in this case is written

$$
S W=\frac{x}{n+y} \int_{\hat{g}}^{\infty}[g-h-c(p)] d F(g)-e(y) .
$$

Taking the derivative of this expression with respect to $y$ (and assuming an interior solution) yields

$$
\frac{-x}{n+y}[\hat{g}-h-c(p)] f(\hat{g})(s / x)-\frac{x}{(n+y)^{2}} \int_{\hat{g}}^{\infty}[g-h-c(p)] d F(g)=e^{\prime}
$$

Note that the left-hand side of this condition, which is the marginal benefit of solicitation (again reflecting the deterrence and diversion effects) must be positive. A necessary condition for this to be true is

$$
\hat{g}<h+c(p)
$$

\footnotetext{
${ }^{12}$ This result is in contrast to that in Polinsky and Shavell (2000, p. 54), which showed that when punishment is exclusively jail time and $p$ is endogenous, the optimal jail term is maximal. The same result would hold here if $y=0$ and $k^{\prime \prime}=0$.
} 
Thus, there is some degree of underdeterrence. This is a standard result, reflecting the fact that deterrence is costly, so crimes are optimally deterred only to the point where the last dollar spent on enforcement (in this case, on $y$ ) equals the net social loss from the marginal crime (given by $h+c(p)-\hat{g}$ ). Generally, therefore, there will be less deterrence (and therefore less criminal solicitation) in a model that values the offender's gain compared to one that does not.

\section{Application to the Entrapment Defense}

Entrapment is a defense that can be raised by a criminal defendant who claims that the solicitation caused him to commit a crime that he otherwise would not have committed. In the context of the model, there are two possible justifications for such a claim (refer to Figure 2). First, the offender could argue that he would have been deterred from seeking a criminal opportunity if not for the solicitation. That is, although $g \geq \hat{g}$ when $y>0$, it would have been the case that $g<\hat{g}$ if $y=0$ (given $g$ and $\hat{g}$ ). Such an argument, however, is not supported by the model. To see why, recall that $\hat{g}$ is increasing in $y$ from (2), implying that if the offender would have been deterred from seeking a criminal opportunity if $y=0$, then he would have been deterred a fortior $i$ when $y>0$. Thus, in the context of the current model, at least, this basis for entrapment cannot be true.

The second possible basis for an entrapment defense is that an offender caught in a sting could argue that, although he was seeking a criminal opportunity (i.e., although $g \geq \hat{g}$ ), he would not have found one but for the solicitation. To evaluate this claim, recall that the probability of locating a criminal opportunity, conditional on searching, is given by $(x+y) /(n+y)$, which is increasing in $y$ (given $n>x)$. Thus, the general strategy of 
criminal solicitation $(y>0)$ does increase the likelihood that an offender will commit a crime of some sort. However, this is a weak argument on the defendant's part because, once he has decided to seek an opportunity, he imposes an expected cost on society given that his failure to commit a crime is only due to his failure to locate an opportunity. Based on this logic, it is perfectly legitimate (in an economic sense) for enforcers to use any reasonable enforcement strategy to reduce those costs.

In fact, the generally accepted definition of entrapment would seem to limit its applicability to the first situation, in which the solicitation induces someone to commit a crime that he never would have committed in "his ordinary environment" (Posner, 2003, p. 231). Individuals seeking a criminal opportunity (those for whom $g \geq \hat{g}$ ) clearly do not fit this definition. (Although they failed to commit a crime, they had criminal intent, or mens rea.) As we saw above, however, individuals who are deterred from even seeking opportunities (those for whom $g<\hat{g}$ ) are never caught in a sting. Thus, the current model does not capture the paradigmatic case of entrapment, which would seem to require some sort of "excessive" enforcement effort by the police, as might arise, for example, if some officers were corrupt or were pursuing an objective other than social welfare. Incorporating such factors into the model is beyond the scope of this paper. ${ }^{13}$

\subsection{The Impact of Entrapment on Law Enforcement}

Although the model sheds no light on why or how some innocent individuals are caught in a sting, it can nevertheless be used to examine the implications of false arrests,

\footnotetext{
${ }^{13}$ There is a large literature on police corruption. See, for example, Becker and Stigler (1974), Mookherjee and Png (1995), Polinsky and Shavell (2001), and Garoupa and Klerman (2004). On the specific relationship between entrapment and police misconduct, see Stevenson (2004), who argues that a newer approach to defining entrapment is based on the behavior of the police rather than the disposition of the offender. Specifically, if the police engage in some form of misconduct, the arrest is deemed to be entrapment regardless of the offender's proclivity.
} 
or "entrapments," on the desirability of sting operations, assuming that such arrests occur with some known frequency. To do this, suppose that a person who chooses not to seek a criminal opportunity will be caught in a sting with a positive probability, which is positively related to the probability that a person actively seeking a criminal opportunity is caught in a sting, $y /(n+y) .{ }^{14}$ Specifically, let the probability that an innocent person is falsely arrested be

$$
q(y, \theta)=\theta\left(\frac{y}{n+y}\right)
$$

where $0<\theta<1$ and $\partial q / \partial y>0$. Thus, increased use of solicitation increases the probability of false arrests, though at a slower rate than it increases the probability of catching an actual offender.

Consider first how the possibility of false arrest affects the incentives of potential offenders to seek criminal opportunities. After realizing $g$, if an individual seeks an offense, his expected return is given by (1), whereas if he does not, his expected return is $-q(y, \theta) s$. He will therefore commit the act if and only if the former exceeds the latter, or if and only if

$$
g \geq[p+(y / x)(1-\theta)] s \equiv \hat{g}(\theta) .
$$

It is clear from a comparison of (2) and (14) that the possibility of false arrest (i.e., $\theta>0$ ) reduces deterrence compared to the case where false arrest is not possible. Intuitively, the possibility of false arrest imposes a cost on the innocent, thereby increasing the incremental value of seeking criminal opportunities.

\footnotetext{
${ }^{14}$ This specification follows that in Polinsky and Shavell (2001, p. 5) regarding the probability that an innocent person will be framed by a corrupt police officer.
} 
In addition to affecting the crime rate, we assume that false arrest entails a social cost associated with wrongful punishment. ${ }^{15}$ Let $r(s)$ be the social cost of imposing a punishment of severity $s$ on an innocent individual, where $r^{r}>0$. Thus, the expected social cost of wrongful punishment is equal to

$$
F(\hat{g}(\theta)) q(y, \theta) r(s)
$$

where $F(\hat{g}(\theta))$ is the fraction of innocent individuals (i.e., those who choose not to seek criminal opportunities). Note that (15) excludes the cost of punishing those individuals who chose to seek a criminal opportunity but failed to locate one (an event that occurs with probability $[1-F(\hat{g}(\theta)][(n-x) /(n+y)])$. Although these individuals are, strictly speaking, innocent of a crime, as noted above, it is debatable whether or not these apprehensions constitute entrapment. For simplicity, we exclude them here.

Adding the term in (15) to social costs in (3) yields the new expression for social costs: ${ }^{16}$

$$
S C^{\prime}=\frac{x}{n+y} \int_{\hat{g}(\theta)}^{\infty}[h+c(p)] d F(g)+F(\hat{g}(\theta)) q(y, \theta) r(s)+e(y)
$$

Consider first optimal solicitation. Taking the derivative of (16) with respect to $y$ and equating it to zero yields

$$
\begin{aligned}
& \frac{x}{n+y}[h+c(p)] f(\hat{g}(\theta))\left(\frac{(1-\theta) s}{x}\right)+\frac{x}{(n+y)^{2}}[1-F(\hat{g}(\theta))][h+c(p)] \\
& =\frac{(1-\theta) s}{x} f(\hat{g}(\theta)) q(y, \theta) r(s)+\frac{\theta n}{(n+y)^{2}} F(\hat{g}(\theta)) r(s)+e^{\prime}
\end{aligned}
$$

\footnotetext{
${ }^{15}$ Harris (1970) was apparently the first to introduce this factor into the economic model of crime. Also see Miceli (1991).

${ }^{16}$ We restrict the analysis in this section to punishment by a fine. Extension to the case of jail is straightforward.
} 
Comparing this condition to (4), we first note that the possibility of false arrests $(\theta>0)$ has an ambiguous effect on the marginal benefit of solicitation (the terms in the first line of (17)). On one hand, it lowers the marginal benefit of solicitation by reducing deterrence (the first term), but on the other, it results in greater savings in social harm and enforcement costs because the crime rate is higher (the second term). In contrast, false arrest increases the marginal cost of solicitation by increasing the expected cost of wrongful punishment. This is reflected by the first two terms on the right-hand side of (17). The first term captures the higher expected error costs due to the decreasing crime rate as $y$ is raised (which means that there are more innocent people who can be wrongly punished), while the second captures the increasing error cost due to the higher arrest rate. On balance, it would seem that the combined effects will cause the optimal use of solicitation to decrease when the possibility of false arrest is taken into account.

Next consider the optimal choice of $p$. The relevant first-order condition is given by

$$
\frac{x}{n+y}[h+c(p)] f(\hat{g}(\theta)) s=\frac{x}{n+y}[1-F(\hat{g}(\theta))] c^{\prime}+f(\hat{g}(\theta)) q(y, \theta) r(s) s .
$$

This differs from condition (5) in two ways. First, the crime rate here is lower due to the diminished deterrence, which lowers the marginal cost of raising $p$ (the first term on the right-hand side). However, this is offset by the extra term on the right-hand side, which is the marginal increase in the probability of wrongful punishment as $p$ is raised because of the deterrence effect (i.e., there are more innocent people who can be falsely arrested). The net effect on $p$ is therefore ambiguous. 
Finally, consider the optimal punishment (fine). In contrast to the earlier analysis with no risk of wrongful punishment, the optimal fine here is no longer necessarily maximal. Instead, it is the solution to the following condition

$$
\begin{aligned}
\frac{x}{n+y}[h+c(p)] & f(\hat{g}(\theta))[p+(y / x)(1-\theta)] \\
& =f(\hat{g}(\theta)) q(y, \theta) r(s)\left[p+(y / x)(1-\theta]+F(\hat{g}(\theta)) q(y, \theta) r^{\prime}\right.
\end{aligned}
$$

The right-hand side of this equation reflects the marginal costs associated with raising the fine. The first term is the marginal increase in error costs as the crime rate decreases, thus subjecting more innocent people to the possibility of wrongful punishment, and the second term is the increase in error costs due to the increasing severity of the sanction, holding the crime rate fixed.

The entrapment defense, if effective in overturning the arrest of truly innocent suspects, has the effect of lowering $\theta$. The preceding results therefore suggest that the defense has the effect of increasing the use of criminal solicitation, and of increasing the severity of criminal punishments of those who are convicted. The effect on the optimal apprehension rate, however, is ambiguous.

\section{Conclusion}

This paper has shown that criminal solicitation, or the tempting of individuals to commit criminal acts by police deception, can be a useful component of an overall law enforcement strategy. Solicitation provides the dual benefits of deterring some offenders from committing crimes altogether (because they anticipate the higher probability that they will be caught), and of diverting others from committing actual crimes that would have imposed harm on victims and necessitated the expenditure of substantial resources on apprehension. The primary drawback of solicitation is the risk that it may "entrap" 
individuals who otherwise would not have committed a crime. By invalidating such false arrests, the entrapment defense therefore provides an important safeguard against excessive use of solicitation by the police.

As noted, a finding of entrapment has traditionally depended on whether or not the defendant had a predisposition to commit the crime for which he was arrested. In a recent article, however, Stevenson (2004) notes that courts are increasingly defining entrapment based on the behavior of the police. Specifically, evidence of police misconduct or overzealousness would result in a finding of entrapment, regardless of the defendant's intentions. This new standard is more compatible with economic theory because it depends on the observable actions of the police rather than the unobservable state of mind of the defendant. ${ }^{17}$ Moreover, the analysis in the current paper provides an economic basis for applying the new standard by defining an optimal level of solicitation, $y^{*}$, against which actual police behavior can be compared. Specifically, entrapment occurs if and only if $y>y^{*}$. Although it may be a difficult task to compute $y^{*}$ for purposes of applying this test, it will almost certainly be easier than attempting to inquire into the defendant's state of mind.

\footnotetext{
${ }^{17}$ For this reason, Stevenson (2004) refers to the old standard as a "subjective test" and the new standard as an "objective test."
} 


\section{References}

Becker, G. (1968) "Crime and Punishment: An Economic Approach,” Journal of Political Economy 76: 169-217.

Becker, G. and G. Stigler (1974) "Law Enforcement, Malfeasance, and Compensation of Enforcers," Journal of Legal Studies 3: 1-18.

Garoupa, N. and D. Klerman (2004) "Corruption and the Optimal Use of Nonmonetary Sanctions," International Review of Law and Economics 24: 219-225.

Harris, J. (1970) "On the Economics of Law and Order," Journal of Political Economy 78: $165-174$.

Miceli, T. (1991) “Optimal Criminal Procedure: Fairness and Deterrence,” International Review of Law and Economics 11: 3-10.

Mookherjee, D. and I. Png (1995) “Corruptible Law Enforcers: How Should They be Compensated?” Economic Journal 105: 145-159.

Posner, R. (2003) Economic Analysis of Law, $6^{\text {th }}$ Edition, New York: Aspen Publishers.

Polinsky, A. M. and S. Shavell (2000) "The Economic Theory of Public Law Enforcement," Journal of Economic Literature 38: 45-76. (2001) "Corruption and Optimal Law Enforcement," Journal of Public Economics 81: 1-24.

Shavell, S. (2004) Foundations of Economic Analysis of Law, Cambridge, MA: Belknap Press of Harvard Univ. Press.

Stevenson, D. (2004) "Entrapment and the Problem of Deterring Police Misconduct," Connecticut Law Review 37: 67-153. 


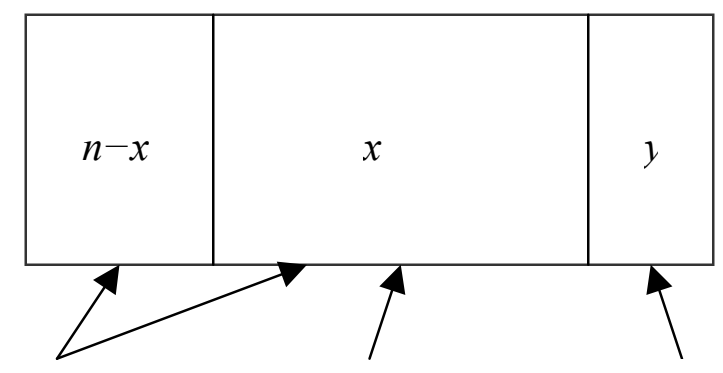

potential criminal opportunities actual criminal stings opportunities

Figure 1. Schematic depiction of a potential offender's criminal opportunities. 


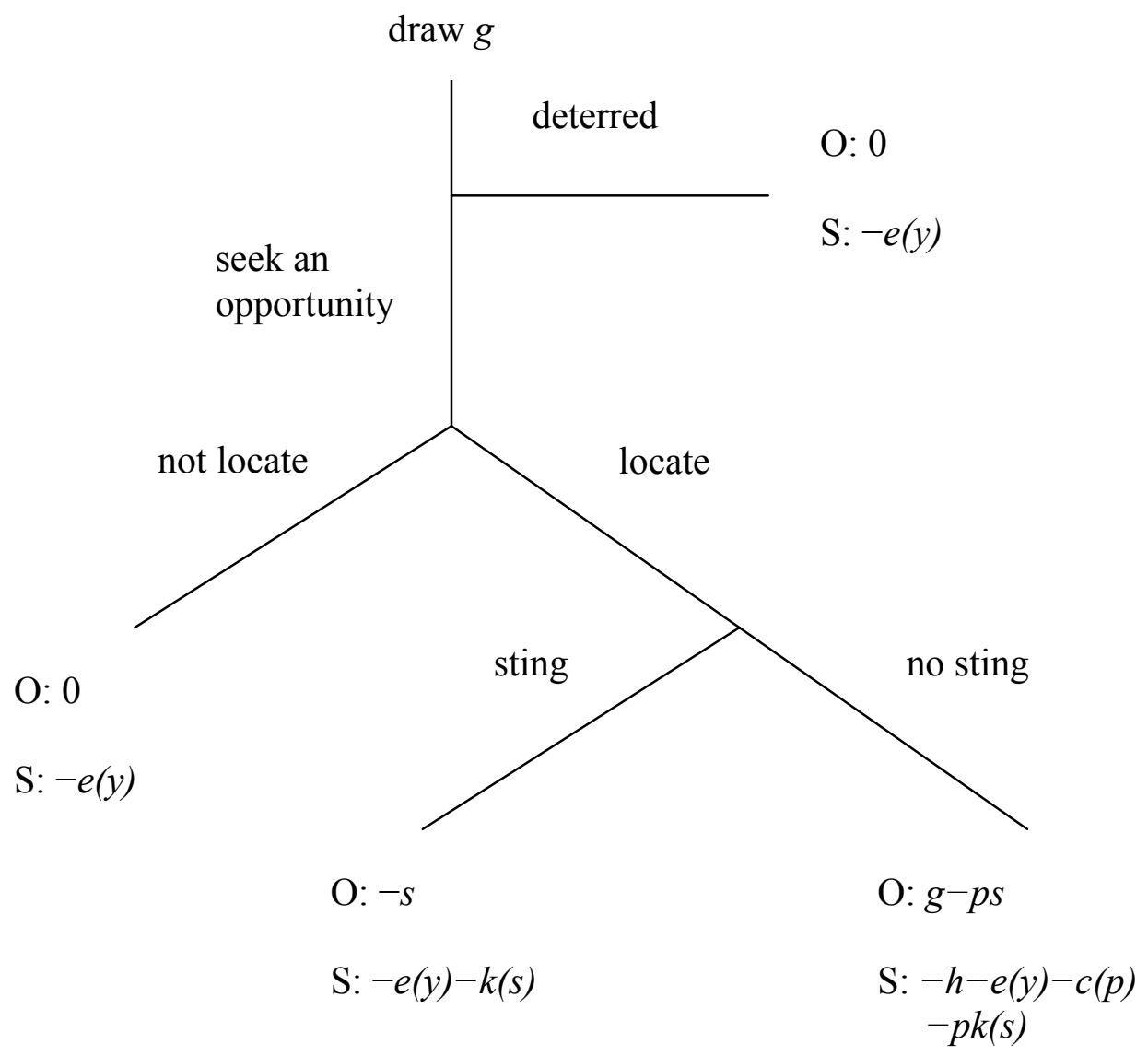

Figure 2. Sequence of decisions of potential offenders. 